\title{
OR-33
}

\section{Chemical Constituents From The Nonpolar Fraction of Goniothalamus Macrophyllus}

\author{
Norkamilah Abdullah ${ }^{1}$, Choo Chee Yan ${ }^{1,}$, Hitotsuyanagi $\mathrm{Y}^{2}$ and Takeya $\mathrm{K}^{2}$ \\ ${ }^{I}$ MedChem Herbal Research Group, Faculty of Pharmacy,Universiti Teknology MARA, 42300 Puncak Alam, Selangor, \\ Malaysia; ${ }^{2}$ Tokyo University of Pharmacy and Life Science,1432-1 Horinouchi, Hachioji,Tokyo 192-0392,Japan; \\ E-mail: choo715@puncakalam.uitm.edu.my
}

Goniothalamus is one of the species from the Annonaceae family consisting of 115 species distributed throughout the tropics and subtropics. Goniothalamus macrophyllus (Blume) Hook. f. \& Thoms. is a medicinal plant used widely in peninsular Malaysia and known by the local as "pokok gajah beranak". Phytochemical studies on goniothalamus species have led to the isolation and characterization of styryllactones, acetogenins, alkaloids and flavanoids. The objective of the study is to identify compounds from the nonpolar fraction from the roots of G. macrophyllus. Dried roots of G. macrophyllus were ground into fine powder using a cutter mill. The ground roots were soaked in $80 \%$ aqueous methanol at room temperature, filtered and the solvent were removed under reduced pressure at $40{ }^{\circ} \mathrm{C}$ to afford crude methanolic extract. The crude extract was further suspended in aqueous methanol and sequentially partitioned with $n$-hexane, chloroform and $n$-butanol. New compounds were isolated and purified from the nonpolar fraction through a combination of preparative HPLC and TLC preparative. The absolute stereo structures were discussed and confirmed by using one (1D) and two- dimensional (2D) NMR, MS, IR, UV-Vis spectroscopy. In conclusion, the nonpolar fraction afforded new compounds.

Keywords: Goniothalamus macrophyllus, Annonaceae, Pokok gajah beranak. 